\title{
Senate urges Bush to act on climate change
}

\section{Quirin Schiermeier}

Despite President George W. Bush's rejection of the Kyoto Protocol on climate change, the US administration is under mounting pressure from Congress to constrain the country's greenhouse-gas emissions.

On 1 August, a powerful senate committee called on the Bush administration to secure the participation of the United States in a revised Kyoto Protocol or other future binding agreement on climate change. The call was made unanimously by the Senate Committee on Foreign Relations.

And on 3 August, two influential senators, John McCain (Republican, Arizona) and Joseph Lieberman (Democrat, Connecticut), jointly announced that they would propose legislation later in the year to set mandatory limits on the United States' greenhouse-gas emissions.

The 19-0 vote by the foreign-relations committee surprised some observers, as several of its members, including Charles Hagel (Republican, Nebraska), have strongly criticized the Kyoto Protocol in the past.

The resolution was proposed by John Kerry (Democrat, Massachusetts) as a nonbinding amendment to a bill funding the Department of State. Its main goal is to bring the United States back to the negotiation table, Kerry says.

The resolution calls on President Bush to put forward a proposal at October's meeting in Marrakesh, Morocco, of the parties to the Kyoto accord in an attempt to secure the United States' participation in a revised
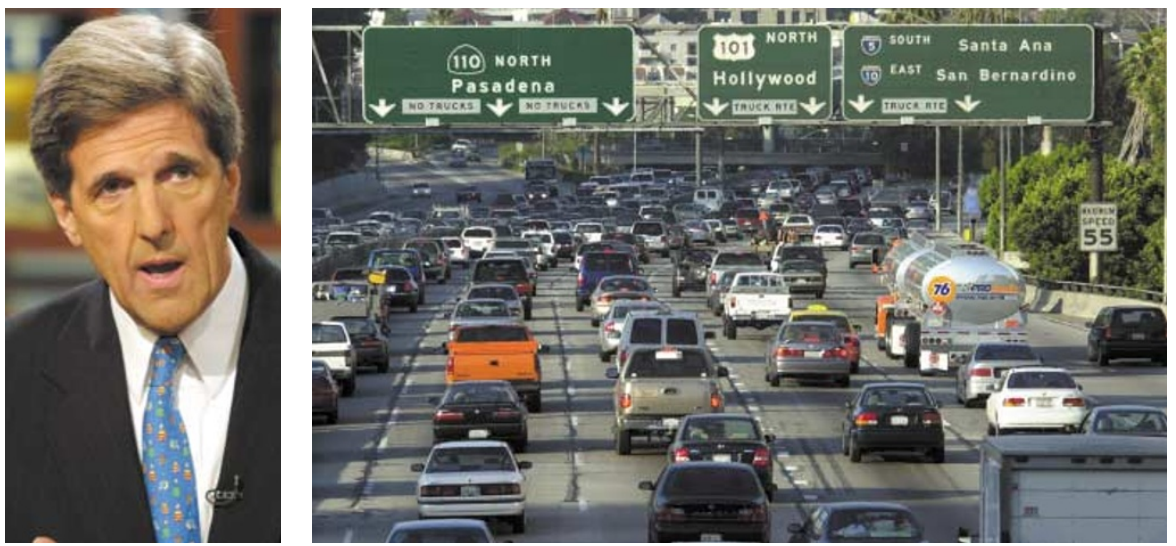

Beating the gridlock: John Kerry hopes the United States will resume talks on carbon emissions.

protocol or other climate-change agreement.

A 1997 Senate resolution, which said that developing nations need to be included in any emissions treaty, should not cause the United States to abandon "its shared responsibility to help find a solution to the global climate-change dilemma", the resolution adds.

Environmental groups praised the resolution, saying that it reflects growing momentum in the Congress for action on climate change. Elliot Diringer of the Pew Center on Global Climate Change, a group that encourages dialogue between industry and the public on the issue, notes that the resolution is the first time the Senate has declared that the United States should be party to a mandatory treaty on climate change.

But the Global Climate Coalition (GCC), which coordinates business opposition to mandatory controls of greenhouse-gas emissions, claims that the new resolution affirms Bush's opposition to the Kyoto accord. "The amendment effectively made the case yet again that any international approach to climate change must involve commitments from developing nations and must not harm American families, workers and communities," says Frank Maisano, a GCC spokesman.

Almost 180 governments signed up to revised Kyoto rules in Bonn last month (see Nature 412, 365; 2001). But the United States - which emits about $25 \%$ of the world's greenhouse gases - rejected the agreement, saying it would unacceptably weaken the country's economy, and that the treaty should not exclude developing countries from binding reduction targets.

\section{Enterprising drug company offers cash for chemicals}

\section{David Adam, London}

Feeling short of funds for that convertible sports car or Caribbean holiday? For those with the right blend of chemistry skills, mountains of cash are now available: all you have to do is synthesize some valuable but awkward molecules on a freelance basis.

Eli Lilly, the Indianapolis-based pharmaceutical company, is offering cash rewards of up to $\$ 100,000$ to researchers who can help it to solve bottlenecks in its drug-discovery programmes. The company has posted a list of more than 20 molecules on the Internet and is asking anyone with the know-how - from postgraduate students to retired university professors - to come up with better ways of making them.

For example, the company needs a new way to synthesize a particularly tricky bicycloketo ethyl ester. Avoid "highly toxic reagents and solvents" and stay within “ $-30^{\circ} \mathrm{C}$ to $150^{\circ} \mathrm{C}$ " and you could earn $\$ 80,000$ - if you can deliver several grams of the ester by 31 October and your method is judged to be the best. Researchers who do not have access to laboratory facilities can also have a go at cracking the conundrums: paper solutions are being accepted for some of them.

Since launching its new web-based venture - called InnoCentive - last month, Lilly says it has had an "extraordinary" response. But the problems clearly leave many would-be contestants scratching their heads: the 900 or so people who have registered for full details have so far submitted just a handful of solutions between them.

The company expects to award its first cash prize early next month, says Alpheus Bingham, vice-president of research and development for Lilly's venture-capital arm, who is heading the project.

Adam Nelson, an organic chemist who specializes in asymmetric synthesis at the University of Leeds in Britain, says the problems do not look too tricky. "They're not fiendishly difficult," he says. "In fact, they're the kind of problems that an average $\mathrm{PhD}$ student will be solving a lot of the time. But clearly there's a methodology gap here." Some lab-scale solutions will prove difficult to scale up to produce the large quantities needed for industry, for example.

Nelson plans to set one of his students to work on one of the problems: a substituted thiophene with a $\$ 70,000$ reward. "It's exactly the sort of chemistry that we do," he says. Researchers in other fields should also stay tuned: Bingham says that more problems, this time in biology and informatics, will be posted soon. http://www.innocentive.com 